\title{
Reimagining Mathematics Education During the COVID-19 Pandemic
}

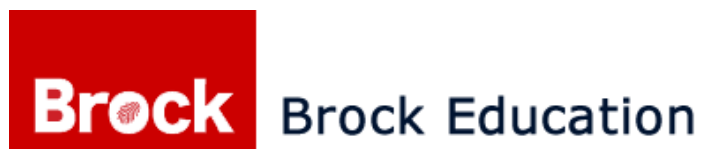

A journal of educational research and practice

2020 Vol. 29 (2) 42-46

https://journals.library.brocku.ca/brocked

\section{Anjali Khirwadkar,* Sheliza Ibrahim Khan, Joyce Mgombelo, Snežana Obradović- Ratković, Wendy Ann Forbes}

Brock University

\begin{abstract}
This essay uses an enactive approach to map out the ways Ontario teachers, students, and parents have reimagined online mathematics education at the K-12 level during the COVID-19 pandemic. The essay highlights the importance of education researchers using an appropriate framework in understanding the emerging mathematics education realities. It encourages education researchers to pay attention to this call to action while recognizing that such an action is not without challenges. To address the challenges, education researchers must engage with the evolving mathematics education environment and community by innovating and reimagining their research tools and techniques.

Keywords: mathematics education, mathematics community, education researchers, enactivism

*akhirwadkar@brocku.ca
\end{abstract}


Mathematics education thrives in face-to-face teaching spaces. This is partially due to the nature of mathematics, "its capacity to compress information into abstract and highly usable forms" (Adler \& Davis, 2006, p. 274), which requires learners to make sense of the abstract mathematical concepts and phenomena building on their experiences. Teachers unpack or decompress mathematics knowledge for their students by implementing pedagogical strategies, such as problem posing/solving, inquiry based teaching, using manipulatives, and collaborative work (Ball \& Bass, 2003).

COVID-19 and its constraints have compelled education stakeholders to move from face-toface delivery to online delivery. As education researchers, we wonder how the online mathematics education environment and mathematics community (students/teachers/parents/policy makers/education researchers) are being reimagined. Given the constraints of the pandemic, we ask the following questions: How are education stakeholders (teachers, parents, students, etc.) adapting within the current mathematics teaching and learning environment? How can an enactive approach frame our understanding of the co-evolving mathematics education environment and community during the pandemic climate?

\section{Mapping the Reality of Mathematics Teaching and Learning During COVID-19}

The shift to a virtual platform across $\mathrm{K}-12$ necessitates the availability of technology remotely to facilitate lesson delivery and ongoing communication among students, teachers, parents, and other stakeholders (Government of Ontario, 2020). Initially, making sure that teachers, students, and parents have access to technological devices was a challenge (Statistics Canada, 2019); therefore, local school boards in Ontario offered technology pick-ups for laptops, iPads, and tablets for those in need, which ensured access for all (Strong, 2020). Furthermore, to help students make sense of abstract mathematical concepts using concrete materials (e.g., measuring sticks, snap cubes, and geoboards), teachers and parents improvised by using household items, finding links to online manipulatives, or using statistics/graphs about the pandemic (Skarky, 2020).

Developing a growth mindset (Boaler, 2016; Dweck, 2008) among students is vital for learning mathematics. It requires consistent and regular guidance from teachers through collaborative opportunities with peers that allow students to witness multiple solutions (Boaler, 2016). This was re-envisioned by creating collaborative teams in the form of breakout groups, where students connected using social platforms/apps.

This section mapped some of the ways mathematics education was reimagined from face-toface to virtual delivery. As we continue grappling with the COVID-19 situation, we turn to an 
enactive approach and propose a contemplative space to make sense of the constraints caused by the pandemic and the opportunities for reimagining research in mathematics education.

\section{Examining the Co-evolving Mathematics Education Environment and Community:}

\section{An Enactive Approach}

We find enactivism helpful for understanding how the mathematics environment and community continue to co-evolve during this time of crisis, recognizing that any pregiven formula to create a mathematics environment and community limits viability.

Enactivism is an approach to cognitive science which challenges theories of mind that continue to perpetuate the dualistic views of mind, such as knowledge/action, human/world, and mind/body binaries. Enactivism claims that cognition emerges from a network of interactions among agents and their environment. From the enactivist perspective, a mathematical community does not simply react to an existing pandemic environment around them; the community and the environment co-emerge. The shift from face-to-face to online teaching and learning environments cannot be seen as a pre-given problem for the community to react to, but rather as an opportunity for the community to "pose the relevant issues that need to be addressed at each moment" (Varela et al., 1993, p. 145) and to reimagine mathematics education within the constraints related to the pandemic. The mathematical community, then, brings forth the world of significance (e.g., mathematics) on a moment to moment basis through their actions and interactions with others and with their environment (Varela et al., 1993), which in our view makes enactivism a relevant lens to study the emerging mathematical environment and community.

Drawing from complexity and an enactive approach, Davis and Simmt (2003) describe the conditions that promote an emergence of a mathematical community, including (a) internal diversity (the members of a community contributing in different ways), (b) redundancy (duplication and excess of the features that are necessary for the emergence of an intelligent collective), (c) decentralized control (no one seems to be in charge of the community and the community organizes itself as if coordinating agents are present at its centre), (d) organized randomness (a structural condition that helps to determine balance between redundancy and internal diversity among members), and (e) neighbour interactions (agents within the complex system affect one another's activity). We use these conditions to understand the emergence of the co-evolving mathematics environment and community in the present context of COVID-19.

The constraints caused by the COVID-19 pandemic provided an opportunity for policy makers, teachers, students, and parents to work together, exchanging ideas, views, experiences, and knowledge. Every member of the community contributed towards meeting the common goal (redundancy) of teaching and learning mathematics. The differing experiences and ideas 
brought forth by stakeholders created an internal diversity, which in turn allowed for innovative ways to learn and teach mathematics. The online platform offered opportunities for neighbouring interactions within the mathematical community to bounce ideas about teaching and learning. Switching to technology in the form of video lessons or situating math problems in real-world contexts were instances where stakeholders interacted with each other.

From an enactivist lens, turning to an online platform was not about adapting face-to-face pedagogical strategies by simply following a prescribed curriculum towards some optimal goal through a prescriptive logic; that is, "what is not allowed is forbidden" (Varela et al., 1993, p. 195). It was, rather, about finding other pedagogical strategies while maintaining the viability of the mathematics education system and moving towards the proscriptive logic - "what is not forbidden is allowed" (Varela et al., 1993, p. 195). Understanding that what is not forbidden is allowed opens a space of opportunities for reimagining mathematics education. The online platform prompted education stakeholders to reimagine possibilities for teaching and learning mathematics as well as structuring the learning environment.

In the context of the pandemic, turning to online teaching practices needed to be done quickly with teachers who may have had little experience with online teaching. Through an enactivist lens, a viable mathematics education system was reimagined. This points to the need for further research to document and conceptualize this phenomenon. Likewise, education researchers need to rethink methodologies and theoretical frameworks in order to understand the emerging educational realities in the context of the COVID-19 pandemic.

\section{Conclusion}

Our enactivist exploration of mathematics education during the COVID-19 pandemic highlighted the importance of an appropriate framework to study emerging educational realities. Education researchers must pay attention to this call to action while recognizing that such an action comes with the challenges requiring time, resources, and funding. The following research questions need further attention: What new possibilities (theoretical and pedagogical) are occasioned by online teaching and learning? What are the dynamics of the co-evolving mathematics education environment and community? What will the mathematics community look like post COVID-19? By addressing these questions, education researchers will provide a practical and theoretical contribution to studying the mathematics environment and community, co-evolving as members of this community. The co-evolution of education researchers and the online mathematics education community is the essence of a viable and sustainable mathematics education system. 


\section{References}

Adler, J., \& Davis, Z. (2006). Opening another black box: Researching mathematics for teaching in mathematics teacher education. Journal for Research in Mathematics Education, 37(4), 270-296. https://doi.org/10.2307/30034851

Ball, D. L., \& Bass, H. (2003). Toward a practice-based theory of mathematical knowledge for teaching. In B. Davis \& E. Simmt (Eds.), Proceedings of the 2002 annual meeting of the Canadian Mathematics Education Study Group (pp. 3-14). CMESG/GDEDM. https://files.eric.ed.gov/fulltext/ED529557.pdf

Boaler, J. (2016). Mathematical mindset: Unleashing students' potential through creative math, inspiring messages and innovative teaching. Jossey-Bass.

Davis, B., \& Simmt, E. (2003). Understanding learning systems: Mathematics education and complexity science. Journal for Research in Mathematics Education, 34(2), 137-167. https://doi.org/10.2307/30034903

Dweck, C. (2008). Mindsets and math/science achievement. Carnegie Corporation of New York, Institute for Advanced Study, Commission on Mathematics and Science Education. https://tinyurl.com/p3vc2fm

Government of Ontario. (2020, August 18). COVID-19: Support for students and parents. https://www.ontario.ca/page/covid-19-support-students-and-parents

Skarky, B. (2020, March 27). Math teacher uses COVID-1 9 to keep students learning during pandemic. RobotLAB. https://www.robotlab.com/blog/math-teacher-uses-covid-19-tokeep-students-learning-during-pandemic

Statistics Canada. (2019, October 29). Canadian internet use survey. The Daily. https://www150.statcan.gc.ca/n1/daily-quotidien/191029/dq191029a-eng.htm

Strong, G. (2020, May 14). The math ain't working: Online schooling not a smooth transition for parents during COVID-19. Global News. https://globalnews.ca/news/6826070/onlineschooling-learning-ontario-parents-coronavirus-covid19/

Varela, F. J., Thompson, E., \& Rosch, E. (1993). The embodied mind: Cognitive science and human experience. The MIT Press. 